\title{
Children with Autism Spectrum Disorder Spent 30 Min Less Daily Time in Moderate-to-Vigorous Physical Activity than Typically Developing Peers: a Meta-Analysis of Cross-sectional Data
}

\author{
Mahdi Rostami Haji Abadi ${ }^{1}$ - Yuwen Zheng ${ }^{1} \cdot$ Tiffany Wharton $^{2} \cdot$ Colleen Dell $^{3} \cdot$ Hassanali Vatanparast ${ }^{4}$. \\ James Johnston $^{5} \cdot$ Saija Kontulainen ${ }^{1}$ (D)
}

Received: 2 October 2020 / Accepted: 27 April 2021 / Published online: 17 July 2021

(C) The Author(s) 2021

\begin{abstract}
It remains unclear if participation in moderate-to-vigorous physical activity (MVPA) differs between children with ASD and typically developing children (TDC). We compared daily MVPA, time spent in MVPA during physical education (PE) and recess, and odds of not meeting MVPA recommendation (60 min/day) between children with ASD and TDC. Nine studies reporting accelerometer-measured MVPA were included in the meta-analyses. MVPA was $30 \mathrm{~min}$ lower/day, $12 \%$ and $8 \%$ lower during PE and recess, respectively, in children with ASD, and they had 4 times higher odds of not meeting MVPA recommendation when compared to TDC. Children with ASD engage in daily MVPA less than TDC and below the guidelines. Tailored interventions to increase MVPA in children with ASD are warranted.
\end{abstract}

Keywords Autism · Asperger's syndrome - Pervasive child development disorders · Physical activity · Physical education · Recess

Autism spectrum disorder (ASD) is a developmental disorder with an estimated global prevalence of $1.5 \%$ (Duchan and Patel 2012; Lyall et al. 2017). Impaired social, communicational, and language skills, as well as restricted and repetitive behaviors, are core symptoms of ASD (World Health Organization 2013). Beyond these core symptoms, impaired motor skills have also been well documented in children with ASD (Downey and Rapport 2012; Fournier et al. 2010; Green et al. 2009; Pan et al. 2009; Whyatt and Craig 2012). These

Saija Kontulainen

saija.kontulainen@usask.ca

1 College of Kinesiology, University of Saskatchewan, 87 Campus Drive, Saskatoon, SK S7N 5B2, Canada

2 School of Rehabilitation Science, University of Saskatchewan, Saskatoon, SK, Canada

3 Department of Sociology, University of Saskatchewan, Saskatoon, SK, Canada

4 College of Pharmacy and Nutrition, University of Saskatchewan, Saskatoon, SK, Canada

5 College of Engineering, University of Saskatchewan, Saskatoon, SK, Canada impairments, combined with personal and physical barriers of physical activity (PA) (Pan et al. 2011a; Obrusnikova and Cavalier 2011; Must et al. 2015), may limit participation in PA and meeting activity guidelines important for well-being and health (Bull et al. 2020; Tremblay et al. 2011).

Evidence of objectively measured moderate-to-vigorous physical activity (MVPA) is important because time spent in MVPA has been related to several health outcomes in children with ASD. Daily MVPA has been positively associated with sleep quality (Garcia et al. 2020; Wachob and Lorenzi 2015), cognitive function (Memari et al. 2017), and manual coordination (Chu et al. 2020), as well as strength and agility (Chu et al. 2020) in children with ASD. In addition, daily MVPA has been negatively associated with subclinical cardiovascular disease risk in children with ASD (Heffernan et al. 2018).

A recent systematic review reported lower PA in children with ASD when compared to TDC (Jones et al. 2017). However, to the best of our knowledge, no meta-analysis has yet been conducted comparing objectively measured MVPA between children with ASD and TDC. Therefore, the primary aim of this meta-analysis was to compare objectively measured daily MVPA between children with ASD and TDC, as well as to examine the odds ratio (ORs) between having ASD and not 
meeting the recommendation of MVPA at least $60 \mathrm{~min} /$ day (Bull et al. 2020; Tremblay et al. 2011). Since school hours are important for the accumulation of MVPA in children (Brooke et al. 2014; Pan et al. 2015; Sandt and Frey 2005), the secondary aim was to compare in-school MVPA, specifically the percentage of time spent in MVPA during PE and recess, between children with ASD and TDC.

\section{Methods}

We followed the Preferred Reporting Items for Systematic Reviews and Meta-Analyses (PRISMA) guidelines (Liberati et al. 2009; Moher et al. 2009) for conducting and reporting our meta-analyses.

\section{Search Strategy}

Three investigators (MR, YZ, TW) independently conducted an electronic search for peer-reviewed publications in three databases (PubMed, SPORTDiscus, and Web of Science) to retrieve all papers investigating the difference in objectively measured daily MVPA between children with ASD and TDC. The search was restricted to full articles in English published from January 1, 1990, to May 31, 2020. We employed "Child*," "Adolescen*," "Youth," "Pediatr*," "Boy,"
"Girl," "Autistic Disorder*," "Autism Spectrum Disorder*," "Autism," "Physical Activit*," "Moderate to Vigorous Physical Activity," and "MVPA" as key terms in the searches. We combined the terms using the boolean operators "OR" and "AND." Table 1 provides the search strategy in detail.

\section{Eligibility Criteria}

We included studies that were published in a peer-reviewed journal, written in English and measured MVPA objectively in participants with ASD (mean age, 6-18 years) (including autism, Asperger syndrome, and pervasive developmental disorder not otherwise specified (PDD-NOS)). We included studies reporting comorbidities (e.g., ADHD). We excluded studies if they did not have a comparison group of TDC. Three investigators, working in groups of two (MR and TW; MR and YZ), selected publications, and disagreements were resolved through a discussion with a fourth investigator (SK) when required.

\section{Data Extraction and Quality Assessment}

Three investigators (MR, TW, and YZ) extracted the study characteristics (design and location), participant characteristics (number, age and sex), the tool used to diagnose ASD, accelerometer characteristics (type, epoch, wear time, the minimum required wear time, measurement units, and cutoff points), daily

Table 1 Detail of search strategy

Database Search details

PubMed $\quad(((()((“ c h i l d * ”[$ All Fields] OR “adolescence*”[All Fields]) OR (((““adolescent”[MeSH Terms] OR “adolescent”[All Fields]) OR “youth”[All Fields]) OR “youths”[All Fields]) OR “youth s”[All Fields])) OR “podiatry*”[All Fields]) OR (“"men”[MeSH Terms] OR “men”[All Fields]) OR "boy"[All Fields])) OR ((“women”[MeSH Terms] OR “women”[All Fields]) OR “girl”[All Fields])) AND ((()(((“"autistic disorder”[MeSH Terms] OR (“autistic”[All Fields] AND “disorder”[All Fields])) OR “autistic disorder”[All Fields]) OR “autistic”[All Fields]) OR “autistics”[All Fields]) OR “autists”[All Fields]) AND “disorder*”[All Fields]) OR ((((((“autism s”[All Fields] OR “autisms”[All Fields]) OR “autistic disorder”[MeSH Terms]) OR (“autistic”[All Fields] AND “disorder”[All Fields])) OR “autistic disorder”[All Fields]) OR “autism”[All Fields]) AND ((“spectrum”[All Fields] OR “spectrum s”[All Fields]) OR “spectrums”[All Fields]) AND “disorder*”[All Fields])) OR (((((“autism s”[All Fields] OR “autisms”[All Fields]) OR “autistic disorder”[MeSH Terms]) OR (“autistic"[All Fields] AND “disorder”[All Fields])) OR “autistic disorder”[All Fields]) OR “autism”[All Fields]))) AND (((()(((“physical examination”[MeSH Terms] OR ("physical”[All Fields] AND “examination”[All Fields])) OR "physical examination”[All Fields]) OR “physical”[All Fields]) OR "physically”[All Fields]) OR “physicals”[All Fields]) AND “activit*”[All Fields]) OR ((()((()(“moderate”[All Fields] OR “moderated”[All Fields]) OR “moderately”[All Fields]) OR “moderates"[All Fields]) OR “moderating”[All Fields]) OR “moderation”[All Fields]) OR “moderational”[All Fields]) OR “moderations"[All Fields]) OR “moderator"[All Fields]) OR “moderators"[All Fields]) AND “vigorous”[All Fields] AND ((c“exercise”[MeSH Terms] OR “exercise”[All Fields]) OR ("physical”[All Fields] AND “activity”[All Fields])) OR “physical activity”[All Fields]))) OR “MVPA”[All Fields])) AND (1990/1/1:2020/5/31[Date Publication] AND “English”[Language])

SPORTDiscus Boolean/Phrase: (child* OR adolescen* OR youth OR pediatr* OR boy OR girl) AND ( autistic disorder* OR autism spectrum disorder* OR autism ) AND ( physical activit* OR moderate to vigorous physical activity OR MVPA)

Limiters - Published Date: 19900101-20200531; Language: English

Expanders - Apply equivalent subjects; Apply related words

Web of Science TOPIC: (child* OR adolescen* OR youth OR pediatr* OR boy OR girl) AND TOPIC: (autistic disorder* OR autism spectrum disorder* OR autism) AND TOPIC: (physical activit* OR moderate to vigorous physical activity OR MVPA) AND YEAR PUBLISHED: (1990-2020) AND LANGUAGE: (English)

Timespan: All years. Indexes: SCI-EXPANDED, SSCI, A\&HCI, CPCI-S, CPCI-SSH, BKCI-S, BKCI-SSH, ESCI, CCR-EXPANDED, IC. 
minutes of MVPA, number of participants who met the daily 60 min of MVPA, and the percentage of time spent in MVPA during PE and recess. We contacted the authors of six articles to request those PA outcomes of interests that were not reported in their published papers (Bandini et al. 2013; Moludi et al. 2019; Pan et al. 2016; Sandt and Frey 2005; Stanish et al. 2017; Tyler et al. 2014). Two authors (Bandini et al. 2013; Stanish et al. 2017) provided the requested data. We estimated means and standard deviation (SD) from figures using GetData Graph Digitizer 2.26 or available data when authors did not respond. Two investigators (MR and YZ) assessed the quality and risk of bias of included studies using the modified version of the Newcastle-Ottawa Quality Assessment Scale (adapted for cross-sectional studies) (Modesti et al. 2016), and the disagreements were resolved through discussion with a third investigator (SK) when required. Studies were scored as good (overall score $>7$, selection domain $\geq 3$, comparability domain $=2$, outcome domain $>2)$, fair $(5-7,2,1,2)$, or poor quality $(<$ 5, 0-1, 0, 0-1) (McPheeters et al. 2012). The good, fair, and poor quality scores suggested a low, moderate, and high risk of bias, respectively (Bano et al. 2020).

\section{Statistical Analysis}

We estimated mean differences (MD) and standardized mean differences (SMD) of MVPA outcomes (daily minutes and the percentage of time spent in MVPA during PE and recess at school) between children with ASD and TDC. We chose to report $\mathrm{MD}$ as a summary statistic due to its easy interpretation (minutes of MVPA) and SMD due to the variety of ways MVPA outcomes were measured across the studies. We performed meta-analyses using random-effects models with the inverse variance method in RevMan (Review Manager Version 5.3, The Cochrane Collaboration, 2014). We reported heterogeneity using a $95 \%$ prediction interval $(\mathrm{PI})$ and I-squared $\left(\mathrm{I}^{2}\right)$. We performed a sensitivity (subgroup) analysis comparing daily MVPA between children with mean age $\leq 9$ vs. $>9$ years. We chose the cutoff age based on the reported decline in daily MVPA after 9 years of age in TDC boys (-8\%) and girls (-10\%) (Farooq et al. 2020). We used pooled odds ratios (ORs) to estimate the odds of not meeting the recommended daily MVPA in children with ASD vs. TDC. We estimated publication bias visually by funnel plot using Comprehensive Meta-Analysis version 3, and we used Duval and Tweedie's Trim and Fill test to estimate the adjusted (or unbiased) pooled SMD and ORs.

\section{Results}

\section{Search Results}

The search produced a total of 1242 citations, and after removing duplicates, 985 titles remained (Fig. 1). Of these, 970 studies were excluded as they did not meet the inclusion criteria after the abstract screening, leaving 15 studies eligible for full-text review. We excluded one study as it did not compare children with ASD with TDC (Boddy et al. 2015), and another study as it measured MVPA subjectively reported by parents (Healy and Garcia 2019). We also excluded three studies (Pan 2008a; Pan et al. 2011b, 2016) as they reported previously published PA outcomes already included in the meta-analysis (Pan 2008b; Pan et al. 2011a, 2015). Another study was excluded as participants' mean age was less than 6 years old (Thomas et al. 2019). Two studies had participants younger than 6 years; however, they were included as their participants' mean age was higher than 6 years (Bandini et al. 2013; Sandt and Frey 2005). We checked the included studies' references for relevant studies, but no additional studies were identified. In total, nine studies met the inclusion criteria for the meta-analyses.

\section{Characteristics of the Included Studies}

Included studies were published between 2005 and 2019 from four countries, including the USA (Bandini et al. 2013; Sandt and Frey 2005; Stanish et al. 2017; Tyler et al. 2014), Taiwan (Pan 2008b; Pan et al. 2011a, 2015), Sweden (Lobenius-Palmér et al. 2018), and Iran (Moludi et al. 2019). The included studies' sample size ranged from 18 (Sandt and Frey 2005) to 825 (LobeniusPalmér et al. 2018). The percentage of girls with ASD ranged from 4\% (Pan 2008b) to 35\% (Tyler et al. 2014) in included studies, and three studies were conducted with only boys (Pan et al. 2011a, 2015; Moludi et al. 2019). Six included studies (Pan et al. 2011a, 2015; Bandini et al. 2013; Tyler et al. 2014; Stanish et al. 2017; Moludi et al. 2019) used validated tools for diagnosis of ASD, including the Autism Diagnostic Observation Schedule (ADOS), the Autistic Diagnostic InterviewRevised (IDI-R), Diagnostic and Statistical Manual of Mental Disorders, Fourth Edition (DSM-IV), or Diagnostic and Statistical Manual of Mental Disorders, Fourth Edition, Text Revision (DSM-IV-TRß). Two studies (Pan 2008b; Lobenius-Palmér et al. 2018) used medical records for diagnosis, and one study (Sandt and Frey 2005) did not describe the procedure for the determination of ASD. Participants with autism, Asperger's syndrome, and PDD-NOS were included in two studies (LobeniusPalmér et al. 2018; Sandt and Frey 2005), whereas three studies (Pan 2008b; Pan et al. 2011a, 2015) included participants with autism and Asperger's syndrome. Four studies did not report the type of ASD in their participants (Bandini et al. 2013; Moludi et al. 2019; Stanish et al. 2017; Tyler et al. 2014). The type of accelerometer, time-sampling interval (epoch), and cutoff point varied in the included studies (Table 2). 
Fig. 1 The PRISMA flow diagram (Liberati et al. 2009; Moher et al. 2009) of the literature search and article selection

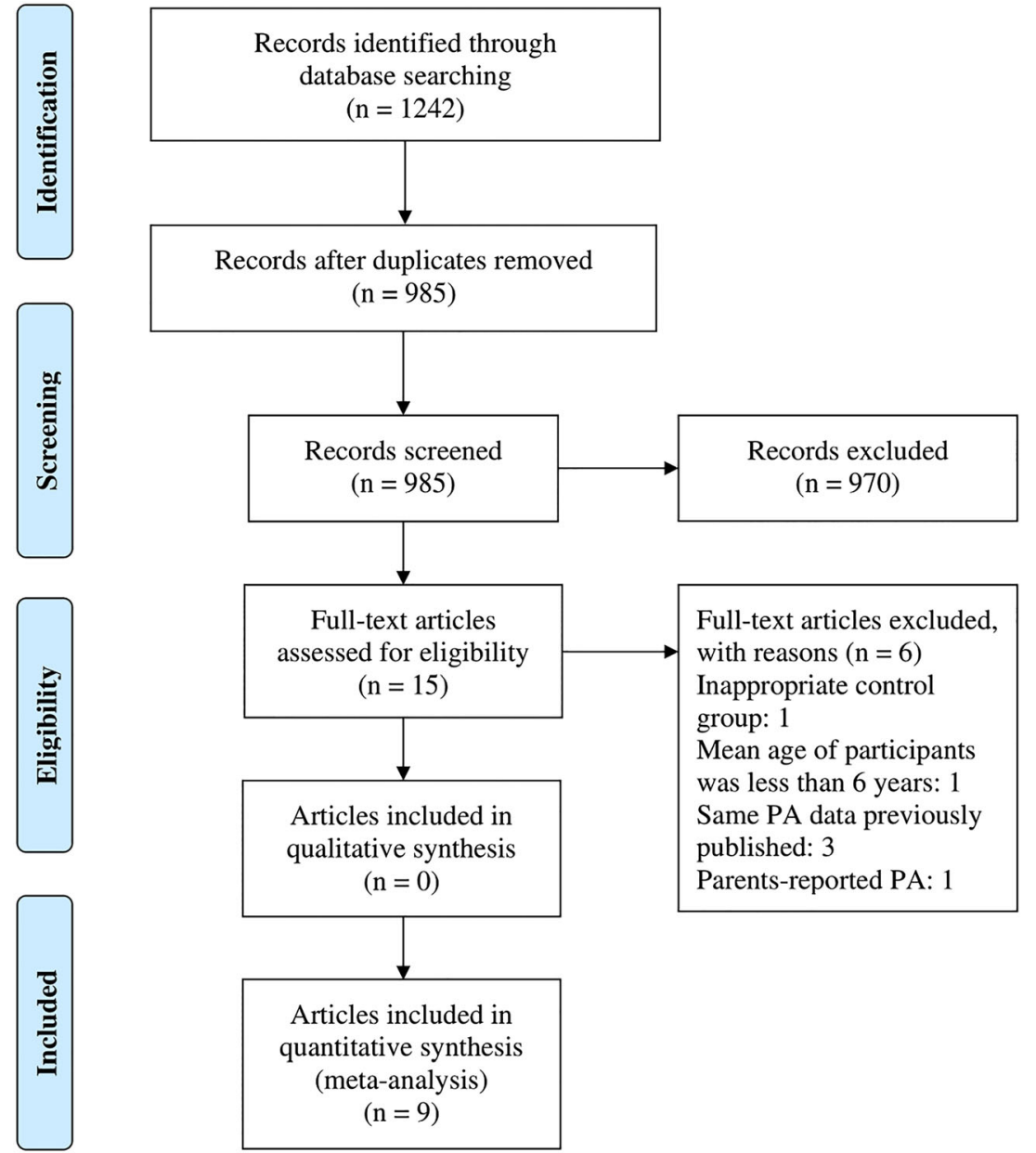

\section{Quality of Included Studies}

The studies' quality scores ranged from 5 (Sandt and Frey 2005) to 8 (Lobenius-Palmér et al. 2018; Pan et al. 2015; Stanish et al. 2017; Tyler et al. 2014) out of 9 points (Table 3). Included studies had either low (4 studies) and moderate ( 5 studies) risk of bias.

\section{Risk of Bias in Included Studies}

Four included studies had a low risk of bias and five had a moderate risk of bias (Table 3). All studies with a low risk of bias also had a low risk of selection, comparability, and outcome bias. Three studies with a moderate risk of bias had either moderate comorbidity bias (Moludi et al. 2019; Pan et al. 2011a) or outcome bias (Bandini et al. 2013). Only one study had a high risk of selection bias (Sandt and Frey 2005).

\section{Daily MVPA}

Children with ASD spent 30 min less daily time in MVPA $(\mathrm{MD}=-30 ; 95 \% \mathrm{CI},-46$ to $-14, P<0.001)$ (Fig. 2) when compared to TDC (SMD $=-0.6 ; 95 \% \mathrm{CI},-0.8$ to $-0.4, P<$ 0.001) (see Appendix, Fig 1). There was no evidence of heterogeneity $(P=0.47)$. The $95 \%$ PI was -0.8 to -0.3 , indicating that the dispersion of effects about pooled SMD was moderate. $\mathrm{I}^{2}$ was 0 , indicating that all of the variances in observed effects were due to sampling error rather than the variance in true effects. There was no evidence of publication bias as no imputed studies were found in re-displayed funnel plots of MVPA, and pooled SMD did not change (Fig. 3a). The subgroup analysis of age indicated no difference in daily MVPA between studies with participants' mean age $>9$ years $(-33$; -51 to $-14, P=0.001)$ and studies with participants' mean age $\leq 9$ years $(-24 ;-54$ to $6, P=0.111)(P=0.739)$.

The meta-analysis indicated that children with ASD had 4 times higher odds $(\mathrm{OR}=4.0 ; 95 \% \mathrm{CI}, 2.5$ to $6.5, P<0.001)$ of 


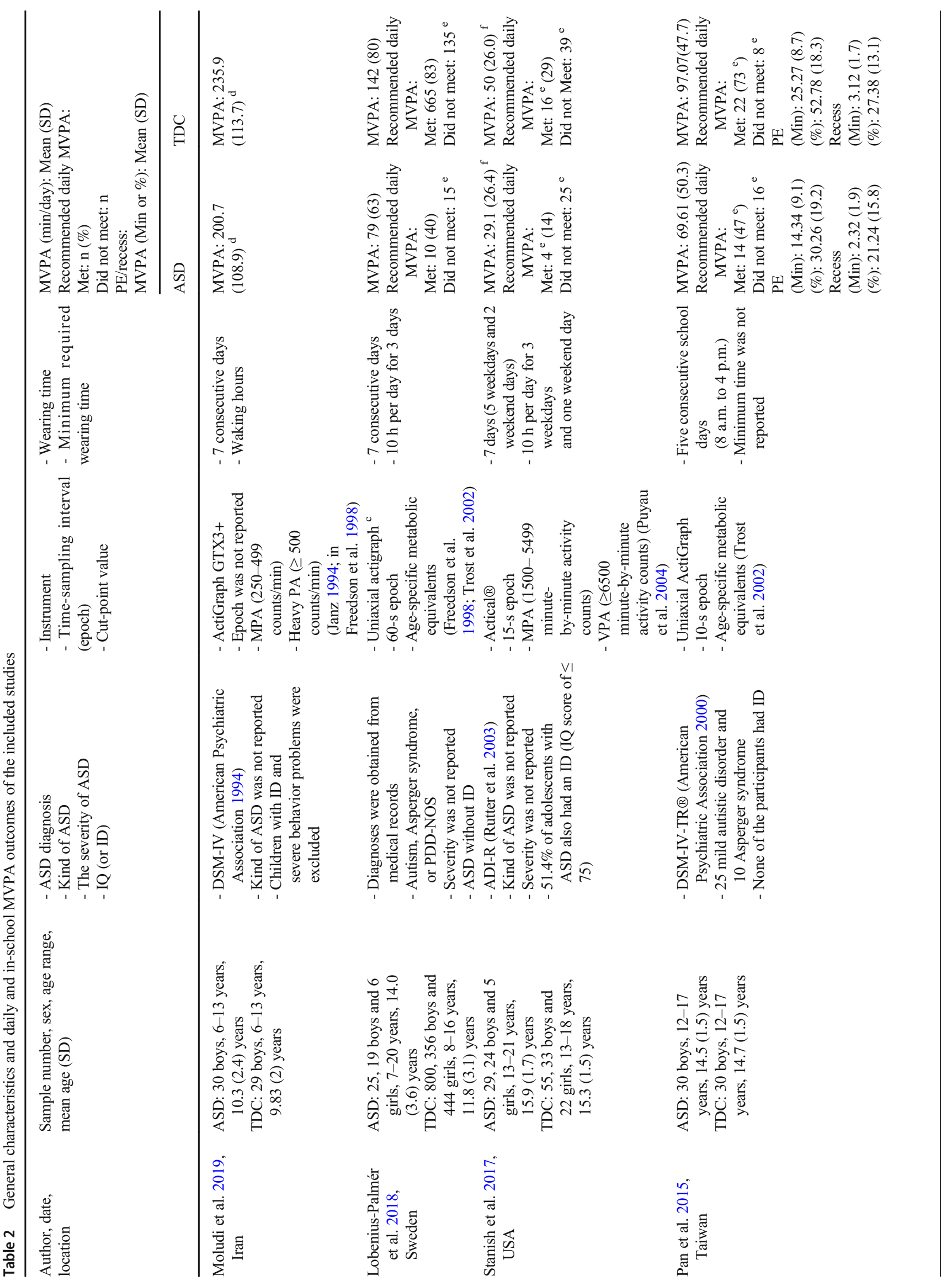




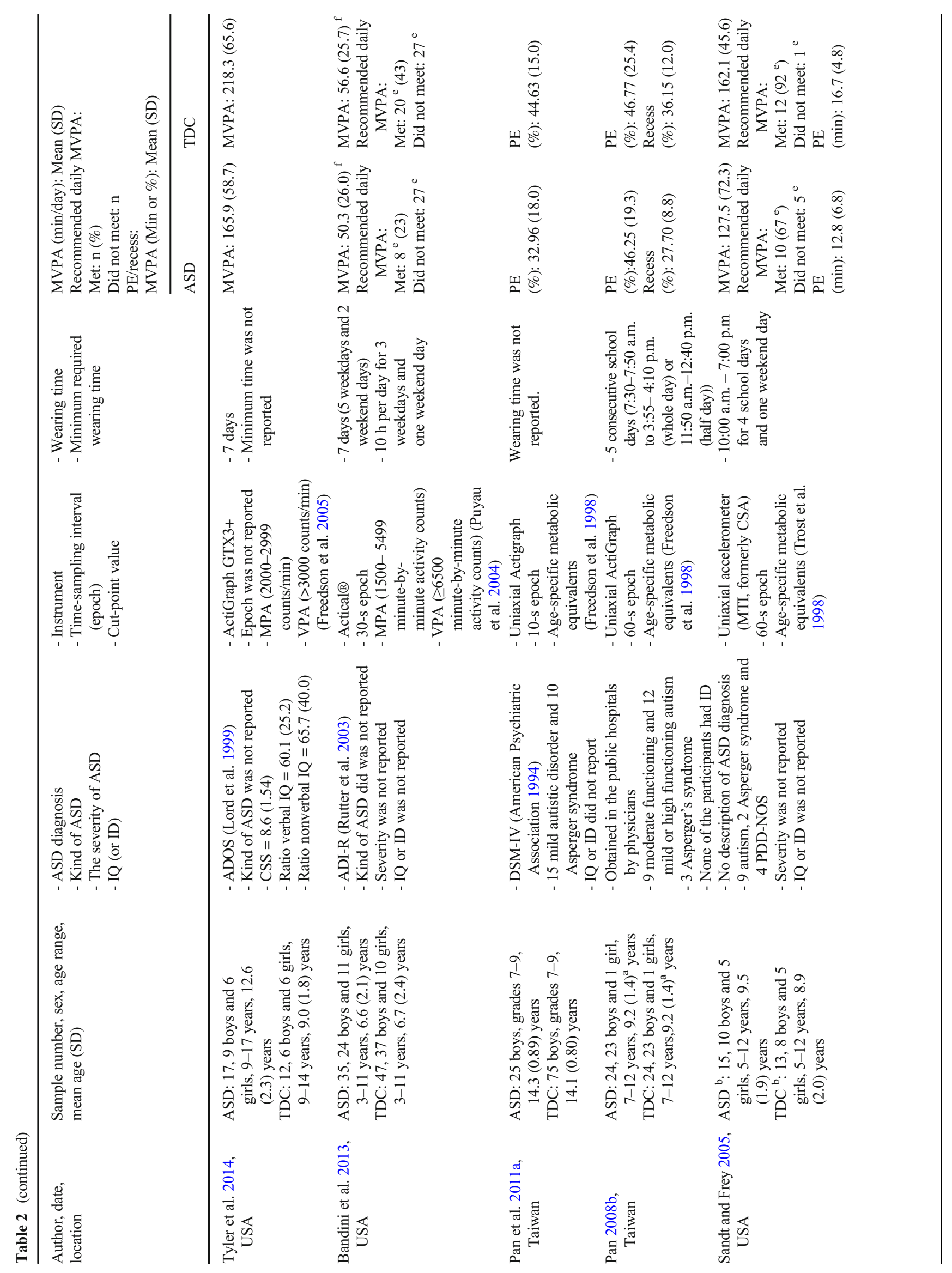




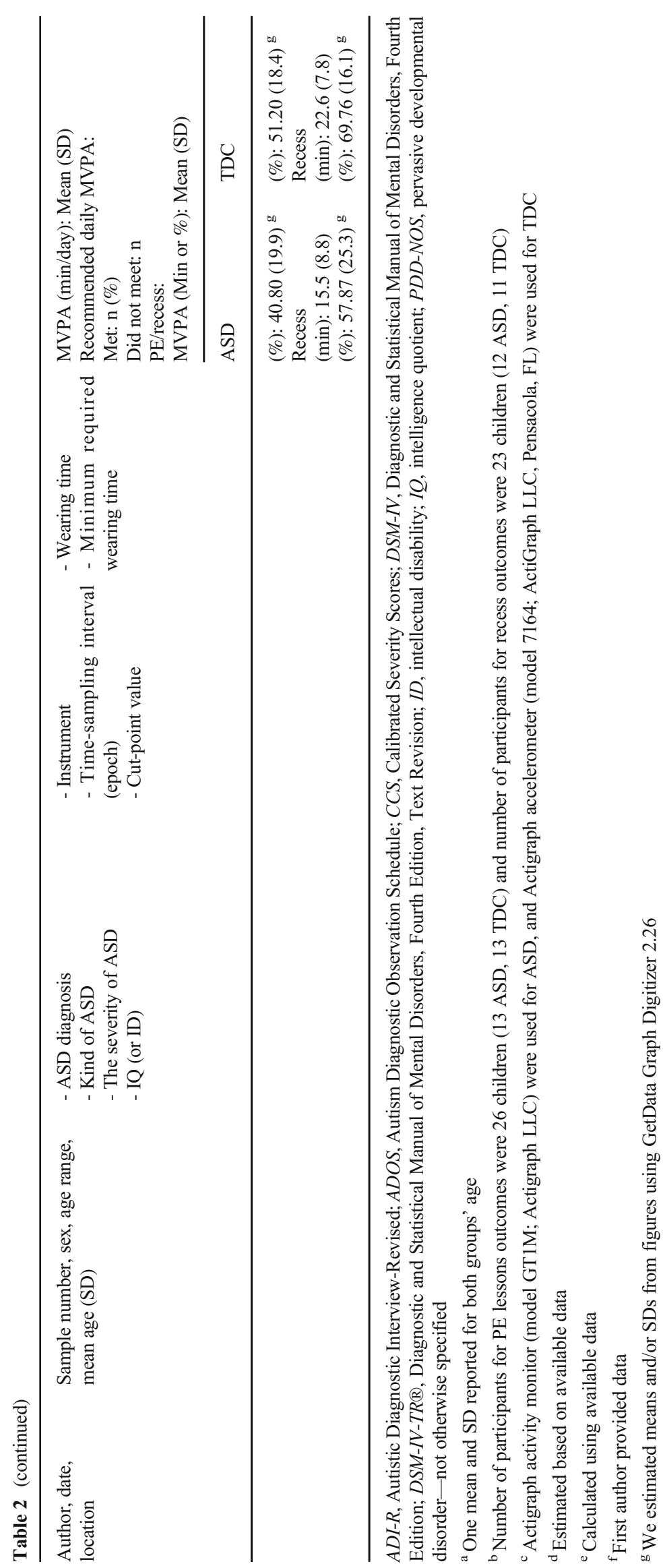




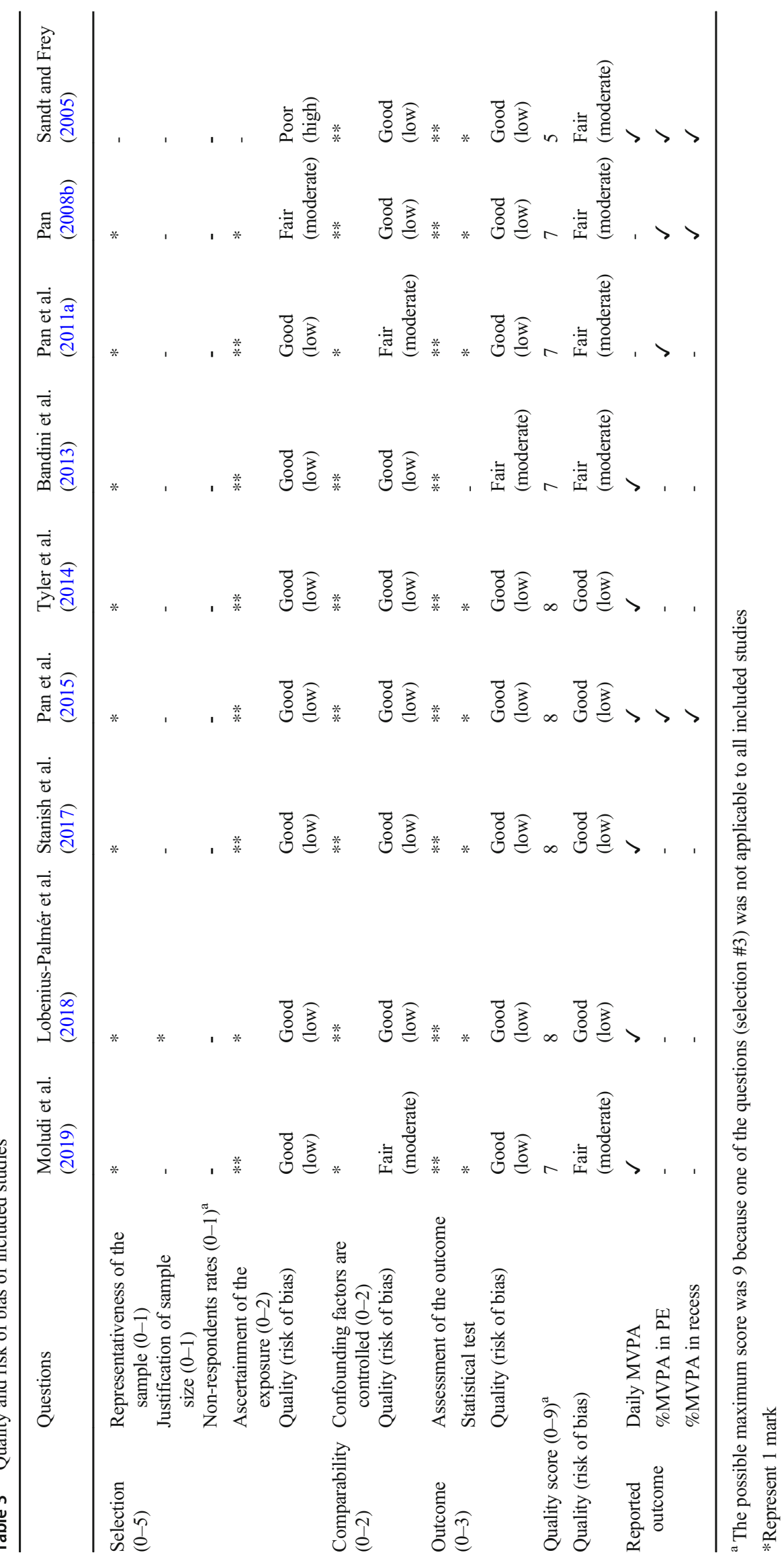




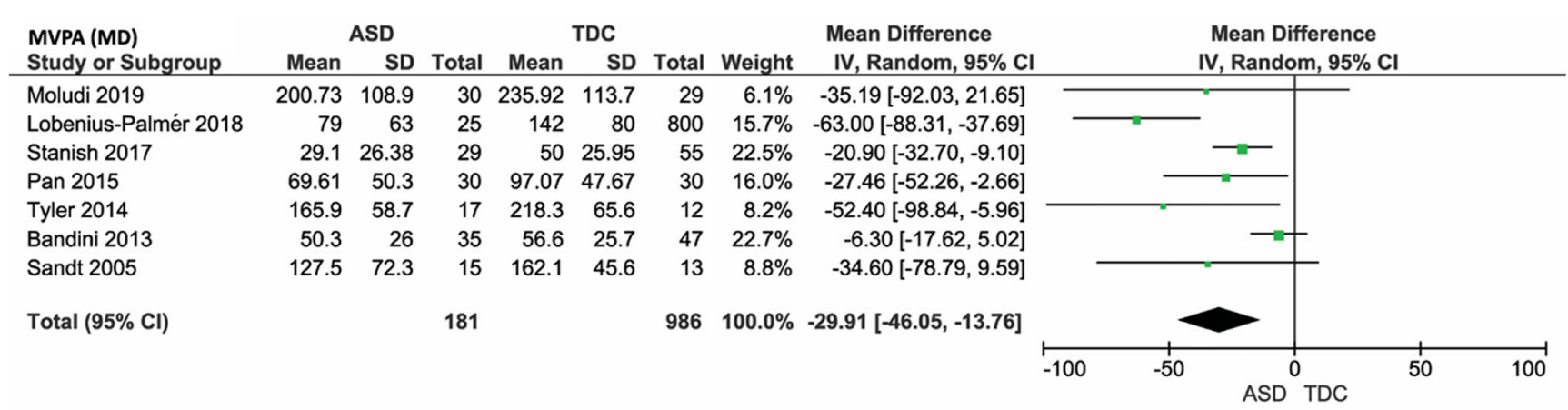

Fig. 2 Forest plot of MD of daily MVPA in children with ASD and TDC

not meeting the recommended daily MVPA than TDC (Fig. 4). No evidence of heterogeneity was exhibited $(P=$ 0.425 ). The $95 \%$ PI was 1.8 to 8.8 , indicating that the dispersion of effects about pooled ORs was substantial; however, children with ASD were less likely to meet recommended daily MVPA across all samples of included studies. The $\mathrm{I}^{2}$ was 0 . There was no evidence of publication bias and pooled ORs did not change (Fig. 3b).

\section{MVPA During PE and Recess}

Children with ASD spent a $12 \%$ lower percentage of time in MVPA (MD $=-12 ; 95 \% \mathrm{CI},-21$ to -3 ) (Fig. 5a) during PE when compared to TDC (SMD $=-0.6 ; 95 \% \mathrm{CI},-1.1$ to -0.1 , $P=0.01$ ) (see Appendix, Fig. 2). The heterogeneity was moderate among studies reporting MVPA in PE $(P=0.04)$. The $95 \%$ PI was -2.7 to 1.4 , indicating substantial dispersion of
Fig. 3 Funnel plot of a daily MVPA and $\mathbf{b}$ not meeting the recommended daily MVPA (60 min) in children with ASD and TDC (a) MVPA

Funnel Plot of Standard Error by Effect Size

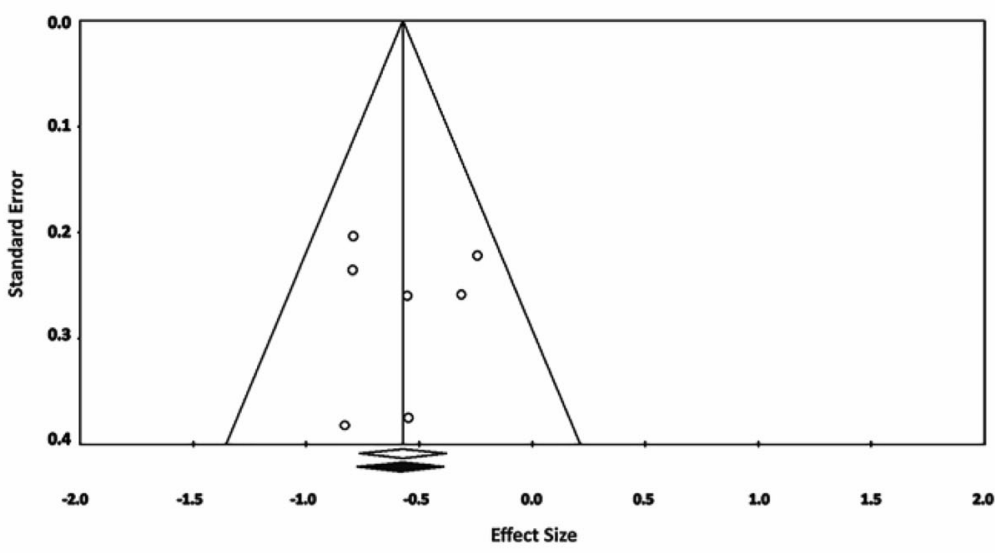

(b) 60 min MVPA Funnel Plot of Standard Error by Effect Size

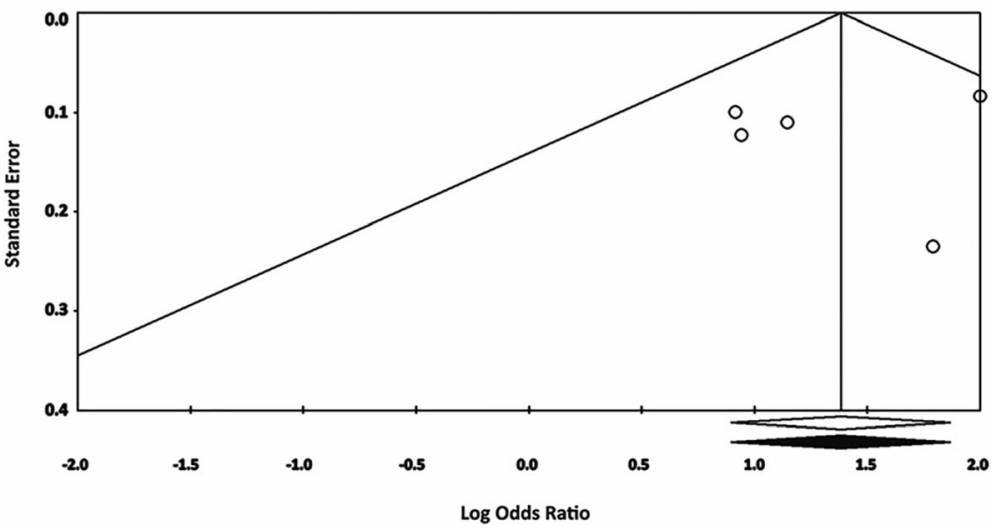




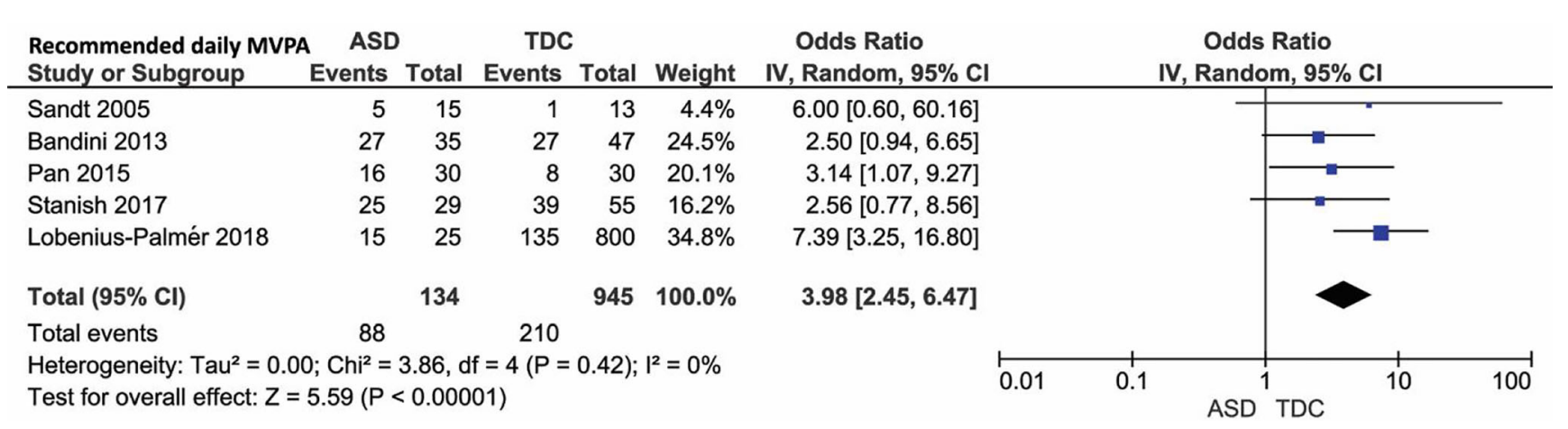

Fig. 4 Forest plot of not meeting the recommended daily MVPA (60 min) in children with ASD and TDC

effects about pooled SMD. The $\mathrm{I}^{2}$ was $65 \%$. There was no evidence of publication bias and pooled SMD did not change (see Appendix, Fig. 3a).

The meta-analysis indicated that children with ASD spent a $8 \%$ lower percentage of recess time in MVPA $(\mathrm{MD}=-8 ; 95 \%$ $\mathrm{CI},-12$ to -3 ) (Fig. $5 \mathrm{~b}$ ) when compared to TDC (SMD = -0.6 ; $95 \%$ CI, -0.9 to $-0.2, P=0.001$ ) (see Appendix, Fig. $2 \mathrm{a})$. There was no evidence of heterogeneity $(P=0.64)$. The $95 \%$ PI was -2.8 to 1.7 , indicating substantial dispersion of effects about the pooled SMD. However, $\mathrm{I}^{2}$ was 0 , indicating that variance in observed effects was due to sampling error rather than the variance in true effects. There was no evidence of publication bias and pooled SMD did not change (see Appendix, Fig. 3b).

\section{Discussion}

The meta-analyses provided a more precise estimate of lower daily and in school MVPA in children with ASD. Results from the meta-analyses indicated that children with ASD spent an average of 30 min less time in MVPA each day, and had 4 times the odds of not meeting the MVPA recommendation when compared to TDC. In school, children with ASD spent about $12 \%$ and $8 \%$ lower percentage of time in MVPA during PE and recess, respectively.

Thirty minutes lower daily MVPA in children with ASD is concerning and clinically important as lower MVPA may adversely affect development and overall health in children with ASD. Physical activity, particularly MVPA, is important for growth and development as well as an essential determinant of physical, mental, cognitive, and social health in children (Janssen and LeBlanc 2010; Poitras et al. 2016; Sterdt et al. 2014). Meeting only the MVPA recommendation, as a key component of the 24-h movement guidelines, has been associated with lower clustering of cardiometabolic risk (Skrede et al. 2019) and related risk factors, including obesity and adiposity (Marques et al. 2016; Roman-Viñas et al. 2016) in children. The difference in daily time spent on MVPA between children with ASD and TDC is about half of the recommended daily MVPA (Bull et al. 2020; Tremblay et al. 2011). This difference may be associated with higher

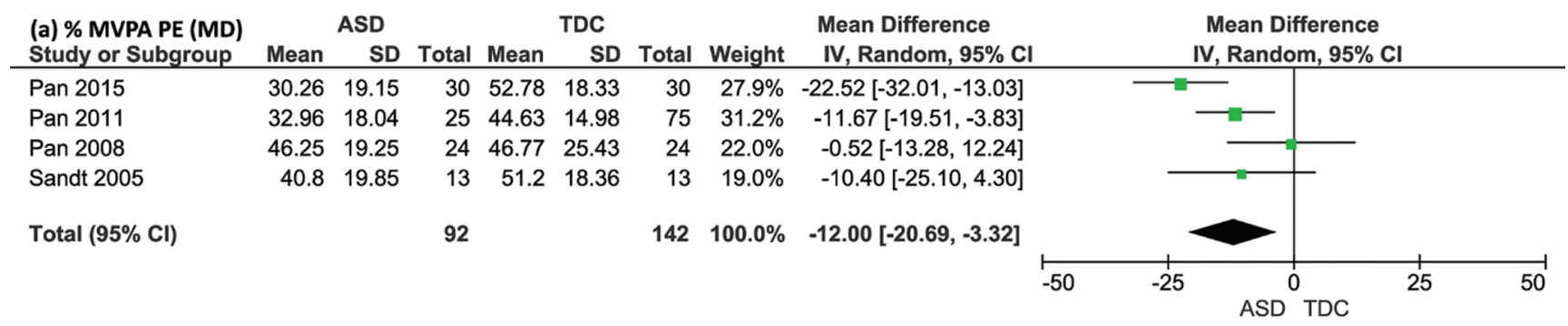

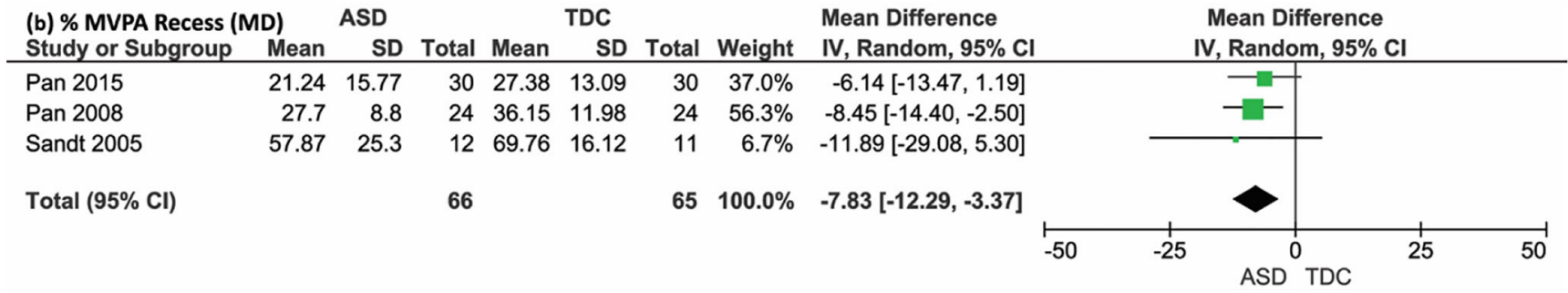

Fig. 5 Forest plot of MD of \%MVPA during $\mathbf{a}$ PE and $\mathbf{b}$ recess in children with ASD and TDC 
overweight and obesity rates reported in children with ASD (Broder-Fingert et al. 2014; Curtin et al. 2005; Egan et al. 2013; Matheson and Douglas 2017). In addition, lower daily MVPA may be related to bone deficits in children with ASD (Rostami Haji Abadi et al. 2021), as daily minutes of MVPA has been positively associated with bone health in childhood and adolescence (Bland et al. 2020; Kehrig et al. 2019).

Meta-analysis indicated that children spent $8-12 \%$ less time in MVPA during recess and PE. School hours occupy a considerable proportion of children's waking hours, and both children with ASD and TDC accumulate more MVPA during than after school hours (Brooke et al. 2014; Pan and Frey 2006), including a higher percentage of time in MVPA during PE and recess (Pan et al. 2015; Sandt and Frey 2005). These differences may partly explain the lower daily MVPA in children with ASD and highlight school activities' importance in children's PA behavior.

Lower MVPA may be related to social interaction impairment, motor skill difficulties, and physical barriers in children with ASD (Bhat et al. 2011; Memari et al. 2017; Must et al. 2015; Pan et al. 2011b; Ruggeri et al. 2020). Social interaction impairment is one of the core symptoms of ASD (World Health Organization 2013). Lower MVPA has been associated with social impairment in children with ASD (Memari et al. 2017; Pan et al. 2011b). Although motor impairment is not a core symptom of ASD, many children with ASD have difficulties in motor skills that may limit their PA participation (Ruggeri et al. 2020). Motor skills impairments may also negatively affect participation in activities necessary for the development of appropriate social and communication skills (Bhat et al. 2011). In addition to these impairments, physical barriers (e.g., lack of a peer partner, parental time, or equipment) may limit PA participation in children with ASD (Obrusnikova and Cavalier 2011). Children with ASD reported more barriers for PA participation than TDC, and the number of barriers correlated negatively with time spent in PA (Must et al. 2015). There is a need to create socially friendly environments to reduce barriers and secure opportunities to encourage PA engagement in children with ASD. For example, animal-assisted interventions have improved social interaction in children with ASD (O'Haire 2013, 2017) and integration of therapy dog teams in a physical activity program has been suggested for children with ASD (Obrusnikova et al. 2012).

There are strengths and limitations in the meta-analyses that warrant discussion. First, a strength of this meta-analysis was the inclusion of studies reporting accelerometermonitored PA. Accelerometers provide an accurate, reliable, and practical measure of PA in both children with disabilities, including ASD (Kim and Yun 2009) and TDC (Rachele et al. 2012; Reilly et al. 2008; Rowlands 2007). Second, all of the included studies, except one, had high quality scores (7 or 8 out of 9 scores) that indicated the limited risk of bias in the included studies. Third, we used both PI and $\mathrm{I}^{2}$ for estimating the heterogeneity to provide more detail about the dispersion of SMD in the included studies (Borenstein 2019). Using only the $\mathrm{I}^{2}$, as a common practice for reporting heterogeneity, is deceptive because $\mathrm{I}^{2}$ is the percentage of the total dispersion due to between-studies variance, but it does not provide any information about the total dispersion (Borenstein 2019). PI provides information about the total dispersion of the SMD in the included studies (Borenstein 2019). Fourth, our age sensitivity analysis suggested that the included studies with participants' mean age below or above 9 years did not affect the daily MVPA meta-analysis consistency. Our meta-analyses also have limitations. First, we chose to include one study (Stanish et al. 2017) that reported adjusted (sex and age) daily MVPA in our meta-analysis as the result did not change after the exclusion of this study. Second, we were not able to examine the effect of the sex as none of the included studies reported sex-specific results, however, low level of heterogeneity in daily MVPA meta-analysis, suggesting that the variability within samples of the included studies did not affect the meta-analysis result. Third, a reliable estimate of heterogeneity needs a reasonably large number of studies; therefore, all reported heterogeneity statistics in our meta-analyses should be interpreted with caution. Fourth, because of the low number of included studies, the power for assessing publication bias was low. In addition to these limitations, it is important to consider that most studies reporting daily and in-school MVPA were from the USA and Taiwan, which may limit the generalizability of the results from this meta-analysis to other countries due to heterogeneity in PA across the globe (Hallal et al. 2012).

\section{Conclusion}

Our meta-analyses results indicated that children with ASD spent an average of 30 min less daily in MVPA and had 4 times the odds of not meeting the daily recommended MVPA compared to TDC. Children with ASD spent about $12 \%$ and $8 \%$ lower percentages of time in MVPA during PE and recess, respectively. Tailored interventions to increase daily and inschool MVPA in children with ASD are warranted.

Supplementary Information The online version contains supplementary material available at https://doi.org/10.1007/s40489-021-00262-x.

Acknowledgements We thank Dr Bandini and Dr Stanish and their colleagues for sharing PA data of their studies (Bandini et al. 2013; Stanish et al. 2017). MR acknowledges a Dean's scholarship from the University of Saskatchewan.

Author Contribution Mahdi Rostami and Saija Kontulainen conceptualized and designed the study. Mahdi Rostami, Yuwen Zhang, and Tiffany 
Wharton performed the literature search and data extraction. Mahdi Rostami analyzed and drafted the manuscript. Mahdi Rostami and Saija Kontulainen interpreted the results and revised the manuscript drafts. All the authors critically revised and approved the final manuscript.

\section{Declarations}

Conflict of Interest The authors declare no competing interests.

Open Access This article is licensed under a Creative Commons Attribution 4.0 International License, which permits use, sharing, adaptation, distribution and reproduction in any medium or format, as long as you give appropriate credit to the original author(s) and the source, provide a link to the Creative Commons licence, and indicate if changes were made. The images or other third party material in this article are included in the article's Creative Commons licence, unless indicated otherwise in a credit line to the material. If material is not included in the article's Creative Commons licence and your intended use is not permitted by statutory regulation or exceeds the permitted use, you will need to obtain permission directly from the copyright holder. To view a copy of this licence, visit http://creativecommons.org/licenses/by/4.0/.

\section{References}

American Psychiatric Association. (1994). Diagnostic and statistical manual of mental disorders (4th ed.). American Psychiatric Association.

American Psychiatric Association. (2000). Diagnostic and statistical manual of mental disorders, text revision (4th ed.). American Psychiatric Association.

Bandini, L. G., Gleason, J., Curtin, C., Lividini, K., Anderson, S. E., Cermak, S. A., et al. (2013). Comparison of physical activity between children with autism spectrum disorders and typically developing children. Autism : the international journal of research and practice, 17(1), 44-54. https://doi.org/10.1177/1362361312437416.

Bano, A., Chaker, L., Muka, T., Mattace-Raso, F. U., Bally, 1., Franco, O. H., et al. (2020). Thyroid function and the risk of fibrosis of the liver, heart, and lung in humans: A systematic review and meta-analysis. Thyroid, 30(6), 806-820. https://doi.org/10.1089/thy.2019.0572.

Bhat, A. N., Landa, R. J., \& Galloway, J. C. (Cole). (2011). Current perspectives on motor functioning in infants, children, and adults with autism spectrum disorders. Physical Therapy, 91(7), 11161129. https://doi.org/10.2522/ptj.20100294.

Bland, V. L., Heatherington-Rauth, M., Howe, C., Going, S. B., \& Bea, J. W. (2020). Association of objectively measured physical activity and bone health in children and adolescents: A systematic review and narrative synthesis. Osteoporosis International, 31(10), 18651894. https://doi.org/10.1007/s00198-020-05485-y.

Boddy, L. M., Downs, S. J., Knowles, Z. R., \& Fairclough, S. J. (2015). Physical activity and play behaviours in children and young people with intellectual disabilities: A cross-sectional observational study. School Psychology International, 36(2), 154-171. https://doi.org/ 10.1177/0143034314564242.

Borenstein, M. (2019). Common mistakes in meta-analysis: and how to avoid them. Biostat Inc.

Broder-Fingert, S., Brazauskas, K., Lindgren, K., Iannuzzi, D., \& Van Cleave, J. (2014). Prevalence of overweight and obesity in a large clinical sample of children with autism. Academic Pediatrics, 14(4), 408-414. https://doi.org/10.1016/j.acap.2014.04.004.
Brooke, H. L., Corder, K., Atkin, A. J., \& van Sluijs, E. M. F. (2014). A systematic literature review with meta-analyses of within- and between-day differences in objectively measured physical activity in school-aged children. Sports Medicine, 44(10), 1427-1438. https://doi.org/10.1007/s40279-014-0215-5.

Bull, F. C., Al-Ansari, S. S., Biddle, S., Borodulin, K., Buman, M. P., Cardon, G., et al. (2020). World Health Organization 2020 guidelines on physical activity and sedentary behaviour. British Journal of Sports Medicine, 54(24), 1451-1462. https://doi.org/10.1136/ bjsports-2020-102955.

Chu, C. H., Tsai, C. L., Chen, F. C., Sit, C. H. P., Chen, P. L., \& Pan, C. Y. (2020). The role of physical activity and body-related perceptions in motor skill competence of adolescents with autism spectrum disorder. Disability and Rehabilitation, 42(10), 1373-1381. https://doi. org/10.1080/09638288.2018.1526334.

Curtin, C., Bandini, L. G., Perrin, E. C., Tybor, D. J., \& Must, A. (2005). Prevalence of overweight in children and adolescents with attention deficit hyperactivity disorder and autism spectrum disorders: A chart review. BMC Pediatrics, 5(1), 48. https://doi.org/10.1186/14712431-5-48.

Downey, R., \& Rapport, M. J. K. (2012). Motor activity in children with autism. Pediatric Physical Therapy, 24(1), 2-20. https://doi.org/10. 1097/PEP.0b013e31823db95f.

Duchan, E., \& Patel, D. R. (2012). Epidemiology of autism spectrum disorders. Pediatric Clinics of North America, 59(1), 27-43. https://doi.org/10.1016/j.pcl.2011.10.003.

Egan, A. M., Dreyer, M. L., Odar, C. C., Beckwith, M., \& Garrison, C. B. (2013). Obesity in young children with autism spectrum disorders: Prevalence and associated factors. Childhood Obesity, 9(2), 125131. https://doi.org/10.1089/chi.2012.0028.

Farooq, A., Martin, A., Janssen, X., Wilson, M. G., Gibson, A., Hughes, A., \& Reilly, J. J. (2020). Longitudinal changes in moderate-tovigorous-intensity physical activity in children and adolescents: A systematic review and meta-analysis. Obesity Reviews, 21(1), 1-15. https://doi.org/10.1111/obr.12953.

Fournier, K. A., Hass, C. J., Naik, S. K., Lodha, N., \& Cauraugh, J. H. (2010). Motor coordination in autism spectrum disorders: A synthesis and meta-analysis. Journal of Autism and Developmental Disorders, 40(10), 1227-1240. https://doi.org/10.1007/s10803010-0981-3.

Freedson, P. S., Melanson, E., \& Sirard, J. (1998). Calibration of the Computer Science and Applications, Inc. accelerometer. Medicine and science in sports and exercise, 30(5), 777-781. https://doi.org/ 10.1097/00005768-199805000-00021.

Freedson, P., Pober, D., \& Janz, K. F. (2005). Calibration of accelerometer output for children. Medicine \& Science in Sports \& Exercise, 37(Supplement), S523-S530. https://doi.org/10.1249/01.mss. 0000185658.28284.ba.

Garcia, J. M., Leahy, N., Rivera, P., Brazendale, K., \& Rice, D. J. (2020). The association among demographic factors, health behaviors and sleep quality in youth with autism spectrum disorder. Disability and Health Journal, 13(3), 100885. https://doi.org/10.1016/j.dhjo.2019. 100885.

Green, D., Charman, T., Pickles, A., Chandler, S., Loucas, T., Simonoff, E., \& Baird, G. (2009). Impairment in movement skills of children with autistic spectrum disorders. Developmental medicine and child neurology, 51(4), 311-316. https://doi.org/10.1111/j.1469-8749. 2008.03242.x

Hallal, P. C., Andersen, L. B., Bull, F. C., Guthold, R., Haskell, W., \& Ekelund, U. (2012). Global physical activity levels: Surveillance progress, pitfalls, and prospects. Lancet (London, England), 380(9838), 247-257. https://doi.org/10.1016/S0140-6736(12) 60646-1.

Healy, S., \& Garcia, J. M. (2019). Psychosocial correlates of physical activity participation and screen-time in typically developing children and children on the autism spectrum. Journal of Developmental 
and Physical Disabilities, 31(3), 313-328. https://doi.org/10.1007/ s10882-018-9642-9.

Heffernan, K. S., Columna, L., Russo, N., Myers, B. A., Ashby, C. E., Norris, M. L., \& Barreira, T. V. (2018). Brief report: Physical activity, body mass index and arterial stiffness in children with sutism spectrum disorder: Preliminary findings. Journal of Autism and Developmental Disorders, 48(2), 625-631. https://doi.org/10. 1007/s10803-017-3358-z.

Janssen, I., \& LeBlanc, A. G. (2010). Systematic review of the health benefits of physical activity and fitness in school-aged children and youth. International Journal of Behavioral Nutrition and Physical Activity, 7(1), 40. https://doi.org/10.1186/1479-5868-7-40.

Janz, K. F. (1994). Validation of the CSA accelerometer for assessing children's physical activity. Medicine and science in sports and exercise, 26(3), 369-375 http://journals.lww.com/00005768199403000-00015.

Jones, R. A., Downing, K., Rinehart, N. J., Barnett, L. M., May, T., McGillivray, J. A., et al. (2017). Physical activity, sedentary behavior and their correlates in children with Autism Spectrum Disorder: A systematic review. PLOS ONE, 12(2), e0172482. https://doi.org/ 10.1371/journal.pone.0172482.

Kehrig, A. M., Björkman, K. M., Muhajarine, N., Johnston, J. D., \& Kontulainen, S. A. (2019). Moderate to vigorous physical activity and impact loading independently predict variance in bone strength at the tibia but not at the radius in children. Applied Physiology, Nutrition, and Metabolism, 44(3), 326-331. https://doi.org/10. 1139/apnm-2018-0406.

Kim, S.-Y., \& Yun, J. (2009). Determining daily physical activity levels of youth with developmental disabilities: Days of monitoring required? Adapted Physical Activity Quarterly, 26(3), 220-235. https://doi.org/10.1123/apaq.26.3.220.

Liberati, A., Altman, D. G., Tetzlaff, J., Mulrow, C., Gøtzsche, P. C., Ioannidis, J. P. A., et al. (2009). The PRISMA statement for reporting systematic reviews and meta-analyses of studies that evaluate health care interventions: Explanation and elaboration. PLoS Medicine, 6(7), e1000100. https://doi.org/10.1371/journal.pmed. 1000100.

Lobenius-Palmér, K., Sjöqvist, B., Hurtig-Wennlöf, A., \& Lundqvist, L.O. (2018). Accelerometer-assessed physical activity and sedentary time in youth with disabilities. Adapted physical activity quarterly : APAQ, 35(1), 1-19. https://doi.org/10.1123/apaq.2015-0065.

Lord, C., Rutter, M., DiLavore, P. C., \& Risi, S. (1999). Autism diagnostic observation schedule-WPS (ADOS-WPS). Los Angeles: Western Psychological Services.

Lyall, K., Croen, L., Daniels, J., Fallin, M. D., Ladd-Acosta, C., Lee, B. K., et al. (2017). The changing epidemiology of autism spectrum disorders. Annual Review of Public Health, 38(1), 81-102. https:// doi.org/10.1146/annurev-publhealth-031816-044318.

Marques, A., Minderico, C., Martins, S., Palmeira, A., Ekelund, U., \& Sardinha, L. B. (2016). Cross-sectional and prospective associations between moderate to vigorous physical activity and sedentary time with adiposity in children. International Journal of Obesity, 40(1), 28-33. https://doi.org/10.1038/ijo.2015.168.

Matheson, B. E., \& Douglas, J. M. (2017). Overweight and obesity in children with autism spectrum disorder (ASD): A critical review investigating the etiology, development, and maintenance of this relationship. Review Journal of Autism and Developmental Disorders, 4(2), 142-156. https://doi.org/10.1007/s40489-0170103-7.

McPheeters, M. L., Kripalani, S., Peterson, N. B., Idowu, R. T., Jerome, R. N., Potter, S. A., \& Andrews, J. C. (2012). Closing the quality gap: revisiting the state of the science (vol. 3: Quality improvement interventions to address health disparities). Rockville (MD): Agency for Healthcare Research and Quality (US); (Evidence Reports/Technology Assessments, No. 208.3.) https://www.ncbi. nlm.nih.gov/books/NBK107315.
Memari, A. H., Mirfazeli, F. S., Kordi, R., Shayestehfar, M., Moshayedi, P., \& Mansournia, M. A. (2017). Cognitive and social functioning are connected to physical activity behavior in children with autism spectrum disorder. Research in Autism Spectrum Disorders, 33(7), 21-28. https://doi.org/10.1016/j.rasd.2016.10.001.

Modesti, P. A., Reboldi, G., Cappuccio, F. P., Agyemang, C., Remuzzi, G., Rapi, S., et al. (2016). Panethnic differences in blood pressure in Europe: A systematic review and meta-analysis. PLOS ONE, 11(1), e0147601. https://doi.org/10.1371/journal.pone.0147601.

Moher, D., Liberati, A., Tetzlaff, J., \& Altman, D. G. (2009). Preferred reporting items for systematic reviews and meta-analyses: The PRISMA statement. PLoS Medicine, 6(7), e1000097. https://doi. org/10.1371/journal.pmed.1000097.

Moludi, J., Ebrahimi, B., Maleki, V., Saiedi, S., Tandoroost, A., JafariVayghyan, H., et al. (2019). Comparison of dietary macro and micronutrient intake with physical activity levels among children with and without autism: A case-control study. Progress in Nutrition, 21(2-S), 49-55. https://doi.org/10.23751/pn.v21i2-S.6578.

Must, A., Phillips, S., Curtin, C., \& Bandini, L. G. (2015). Barriers to physical activity in children with autism spectrum disorders: Relationship to physical activity and screen time. Journal of physical activity \& health, 12(4), 529-534. https://doi.org/10.1123/jpah. 2013-0271.

O’Haire, M. E. (2013). Animal-assisted intervention for autism spectrum disorder: A systematic literature review. Journal of Autism and Developmental Disorders, 43(7), 1606-1622. https://doi.org/10. 1007/s10803-012-1707-5.

O'Haire, M. E. (2017). Research on animal-assisted intervention and autism spectrum disorder, 2012-2015. Applied Developmental Science, 21(3), 200-216. https://doi.org/10.1080/10888691.2016. 1243988.

Obrusnikova, I., \& Cavalier, A. R. (2011). Perceived barriers and facilitators of participation in after-school physical activity by children with autism spectrum disorders. Journal of Developmental and Physical Disabilities, 23(3), 195-211. https://doi.org/10.1007/ s10882-010-9215-z.

Obrusnikova, I., Bibik, J. M., Cavalier, A. R., \& Manley, K. (2012). Integrating therapy dog teams in a physical activity program for children with autism spectrum disorders. Journal of Physical Education, Recreation \& Dance, 83(6), 37-48. https://doi.org/10. 1080/07303084.2012.10598794.

Pan, C. Y. (2008a). Objectively measured physical activity between children with autism spectrum disorders and children without disabilities during inclusive recess settings in Taiwan. Journal of Autism and Developmental Disorders, 38(7), 1292-1301. https://doi.org/ 10.1007/s10803-007-0518-6.

Pan, C. Y. (2008b). School time physical activity of students with and without autism spectrum disorders during PE and recess. Adapted Physical Activity Quarterly, 25(4), 308-321. https://doi.org/10. 1123/apaq.25.4.308.

Pan, C. Y., \& Frey, G. C. (2006). Physical activity patterns in youth with autism spectrum disorders. Journal of Autism and Developmental Disorders, 36(5), 597-606. https://doi.org/10.1007/s10803-0060101-6.

Pan, C. Y., Tsai, C. L., \& Chu, C. H. (2009). Fundamental movement skills in children diagnosed with autism spectrum disorders and attention deficit hyperactivity disorder. Journal of Autism and Developmental Disorders, 39(12), 1694-1705. https://doi.org/10. 1007/s10803-009-0813-5.

Pan, C. Y., Tsai, C. L., Chu, C. H., \& Hsieh, K. W. (2011a). Physical activity and self-determined motivation of adolescents with and without autism spectrum disorders in inclusive physical education. Research in Autism Spectrum Disorders, 5(2), 733-741. https://doi. org/10.1016/j.rasd.2010.08.007.

Pan, C. Y., Tsai, C. L., \& Hsieh, K. W. (2011b). Physical activity correlates for children with autism spectrum disorders in middle school 
physical education. Research Quarterly for Exercise and Sport, 82(3), 491-498. https://doi.org/10.1080/02701367.2011.10599782.

Pan, C. Y., Hsu, P. J., Chung, I. C., Hung, C. S., Liu, Y. J., \& Lo, S. Y. (2015). Physical activity during the segmented school day in adolescents with and without autism spectrum disorders. Research in Autism Spectrum Disorders, 15-16, 21-28. https://doi.org/10.1016/ j.rasd.2015.04.003.

Pan, C. Y., Tsai, C. L., Chu, C. H., Sung, M. C., Ma, W. Y., \& Huang, C. Y. (2016). Objectively measured physical activity and health-related physical fitness in secondary school-aged male students with autism spectrum disorders. Physical Therapy, 96(4), 511-520. https://doi. org/10.2522/ptj.20140353.

Poitras, V. J., Gray, C. E., Borghese, M. M., Carson, V., Chaput, J.-P., Janssen, I., et al. (2016). Systematic review of the relationships between objectively measured physical activity and health indicators in school-aged children and youth. Applied Physiology, Nutrition, and Metabolism, 41(6 (Suppl. 3)), S197-S239. https:// doi.org/10.1139/apnm-2015-0663.

Puyau, M. R., Adolph, A. L., Vohra, F. A., Zakeri, I., \& Butte, N. F. (2004). Prediction of activity energy expenditure using accelerometers in children. Medicine and Science in Sports and Exercise, 36(9), 1625-1631. https://doi.org/10.1249/01.MSS.0000139898.30804. 60.

Rachele, J. N., McPhail, S. M., Washington, T. L., \& Cuddihy, T. F. (2012). Practical physical activity measurement in youth: A review of contemporary approaches. World Journal of Pediatrics, 8(3), 207-216. https://doi.org/10.1007/s12519-012-0359-z.

Reilly, J. J., Penpraze, V., Hislop, J., Davies, G., Grant, S., \& Paton, J. Y. (2008). Objective measurement of physical activity and sedentary behaviour: Review with new data. Archives of disease in childhood, 93(7), 614-619. https://doi.org/10.1136/adc.2007.133272.

Roman-Viñas, B., Chaput, J.-P., Katzmarzyk, P. T., Fogelholm, M., Lambert, E. V, Maher, C., et al. (2016). Proportion of children meeting recommendations for 24-hour movement guidelines and associations with adiposity in a 12-country study. International Journal of Behavioral Nutrition and Physical Activity, 13(1), 123. https://doi.org/10.1186/s12966-016-0449-8

Rostami Haji Abadi, M., Neumeyer, A., Misra, M., \& Kontulainen, S. (2021). Bone health in children and youth with ASD: a systematic review and meta-analysis. Osteoporosis International. https://doi. org/10.1007/s00198-021-05931-5.

Rowlands, A. V. (2007). Accelerometer assessment of physical activity in children: An update. Pediatric Exercise Science, 19(3), 252-266. https://doi.org/10.1123/pes.19.3.252.

Ruggeri, A., Dancel, A., Johnson, R., \& Sargent, B. (2020). The effect of motor and physical activity intervention on motor outcomes of children with autism spectrum disorder: A systematic review. Autism, 24(3), 544-568. https://doi.org/10.1177/1362361319885215.

Rutter, M., Le Couteur, A., \& Lord, C. (2003). Autism diagnostic interview-revised (Vol. 29). Western Psychological Services.

Sandt, D. D. R., \& Frey, G. C. (2005). Comparison of physical activity levels between children with and without autistic spectrum disorders. Adapted Physical Activity Quarterly, 22(2), 146-159. https:// doi.org/10.1123/apaq.22.2.146.
Skrede, T., Steene-Johannessen, J., Anderssen, S. A., Resaland, G. K., \& Ekelund, U. (2019). The prospective association between objectively measured sedentary time, moderate-to-vigorous physical activity and cardiometabolic risk factors in youth: A systematic review and meta-analysis. Obesity Reviews, 20(1), 55-74. https://doi.org/10. 1111/obr.12758.

Stanish, H. I., Curtin, C., Must, A., Phillips, S., Maslin, M., \& Bandini, L. G. (2017). Physical activity levels, frequency, and type among adolescents with and without autism spectrum disorder. Journal of Autism and Developmental Disorders, 47(3), 785-794. https://doi. org/10.1007/s10803-016-3001-4.

Sterdt, E., Liersch, S., \& Walter, U. (2014). Correlates of physical activity of children and adolescents: A systematic review of reviews. Health Education Journal, 73(1), 72-89. https://doi.org/10.1177/ 0017896912469578

Thomas, S., Hinkley, T., Barnett, L. M., May, T., \& Rinehart, N. (2019). Young children with ASD participate in the same level of physical activity as children without ASD: Implications for early intervention to maintain good health. Journal of Autism and Developmental Disorders, 49(8), 3278-3289. https://doi.org/10.1007/s10803-01904026-9.

Tremblay, M. S., Warburton, D. E. R., Janssen, I., Paterson, D. H., Latimer, A. E., Rhodes, R. E., et al. (2011). New Canadian physical activity guidelines. Applied Physiology, Nutrition, and Metabolism, 36(1), 36-46. https://doi.org/10.1139/H11-009.

Trost, S. G., Ward, D. S., Moorehead, S. M., Watson, P. D., Riner, W., \& Burke, J. R. (1998). Validity of the computer science and applications (CSA) activity monitor in children. Medicine and science in sports and exercise, 30(4), 629-633. https://doi.org/10.1097/ 00005768-199804000-00023.

Trost, S. G., Pate, R. R., Sallis, J. F., Freedson, P. S., Taylor, W. C., Dowda, M., \& Sirard, J. (2002). Age and gender differences in objectively measured physical activity in youth. Medicine and science in sports and exercise, 34(2), 350-355. https://doi.org/10. 1097/00005768-200202000-00025.

Tyler, K., MacDonald, M., \& Menear, K. (2014). Physical activity and physical fitness of school-aged children and youth with autism spectrum disorders. Autism Research and Treatment, 2014, 1-6. https:// doi.org/10.1155/2014/312163.

Wachob, D., \& Lorenzi, D. G. (2015). Brief report: Influence of physical activity on sleep quality in children with autism. Journal of Autism and Developmental Disorders, 45(8), 2641-2646. https://doi.org/ 10.1007/s10803-015-2424-7.

Whyatt, C. P., \& Craig, C. M. (2012). Motor skills in children aged 7-10 years, diagnosed with autism spectrum disorder. Journal of Autism and Developmental Disorders, 42(9), 1799-1809. https://doi.org/ 10.1007/s10803-011-1421-8.

World Health Organization. (2013). Autism spectrum disorders \& other developmental disorders. World Health Organization http://www. who.int/mental_health/maternal-child/autism_report/en/.

Publisher's Note Springer Nature remains neutral with regard to jurisdictional claims in published maps and institutional affiliations. 